\title{
INFLUÊ NCIA DA MISTURA DE SULFATO DE AMÔNIO COM URÉIA SOBRE A VOLATILIZAÇÃO DE NITROGÊNIO AMONIACAL (1)
}

\author{
G. C. VITTI ${ }^{(2)}$, J . E. TAVARES J r. ${ }^{(3)}$, P. H. C. LUZ(4), \\ J . L. FAVARIN ${ }^{(5)} \&$ M. C. G. COSTA ${ }^{(6)}$
}

\begin{abstract}
RESUMO
Com o objetivo de avaliar a influência da mistura de sulfato de amônio com uréia sobre a volatilização de nitrogênio amoniacal $\left(\mathrm{N}-\mathrm{NH}_{3}\right)$, realizou-se um experimento em laboratório climatizado do Departamento de Solos e Nutrição de Plantas (E SALQ/USP). Em um delineamento inteir amente casualizado, foram utilizados cinco tratamentos com cinco repetições. Cada tratamento foi obtido pela mistura de uréia $(330 \mathrm{mg})$ com sulfato de amônio $(0,75,150,225$ e $300 \mathrm{mg})$. As misturas de fertilizantes foram aplicadas na superfície do solo (Latossolo Vermelho distrófico, textura média/arenosa) contido em recipientes plásticos de $400 \mathrm{~cm}^{3}$. O N-NH $\mathrm{NH}_{3}$, volatilizado aos 3, 8, 15 e 23 dias da incubação, foi coletado em recipiente com ácido sulfúrico e indicador alaranjado de metila. Variáveis que influenciam a qualidade da mistura de ferti lizantes, como higroscopicidade, granulometria e ângulo de repouso, também foram avaliadas. A volatilização do $\mathrm{N}$ - $\mathrm{NH}_{3}$ depende do pH do solo. A mistura de uréia $(330 \mathrm{mg})$ com sulfato de amônio (300 mg) reduziu significativamente as perdas de $\mathrm{N}-\mathrm{NH}_{3}$ sem afetar a qualidade da mistura em relação aos atributos físico-químicos avaliados, apresentando eficiência técnica e agronômica para o fim proposto.
\end{abstract}

Termos de indexação: fontes de nitrogênio, amônia, mistura de fertilizantes.

(1) Trabalho de Iniciação Científica do segundo autor, financiado pela FAPESP. Recebido para publicação em agosto de 2001 e aprovado em fevereiro de 2002.

(2) Professor Titular do Departamento de Solos e Nutrição de Plantas, Escola Superior de Agricultura "Luiz de Queiroz" - ESALQ/ USP. Av Pádua Dias 11, Caixa Postal 9, CEP 13418-900 Piracicaba (SP). E-mail: gcvitti@carpa.ciagri.usp.br

(3) Mestrando do Departamento de Produção Vegetal, ESALQ/USP. E-mail: julio_tavares@zipmail.com.br

(4) Professor do Departamento de Zootecnia, Faculdade de Zootecnia e Engenharia deAlimentos - FZEA/USP. Rua Duque de Caxias, Norte 225 CEP 13635-900 Pirassununga (SP). E-mail: phcerluz@usp.br

(5) Professor Dr. do Departamento de Produção Vegetal, ESALQ/USP. E-mail: jlfavari@carpa.ciagri.usp.br

(6) Mestranda do Departamento de Solos e Nutrição de Plantas, ESALQ/USP. E-mail: mcgcosta@carpa.ciagri.usp.br 


\title{
SUMMARY: INFLUENCE OF AMMONIUM SULFATE IN MIXTURE WITH UREA ON THE VOLATILIZATION OF $\mathrm{NH}_{3}-\mathrm{N}$
}

\begin{abstract}
The objective of this study was to evaluate the influence of addition of ammonium sulfatein mixture with urea on thevol atilization of $\mathrm{NH}_{3}-\mathrm{N}$. An experiment was carried out under control led laboratory conditions at theSoil and Plant Nutrition Department (ESALQ/ USP). The experimental design was completely randomized with five replications and five treatments. Each treatment was obtained by the mi xture of urea $(330 \mathrm{mg})$ with ammonium sul fateat different rates $(0,75,150,225$ and $300 \mathrm{mg})$. Thefertilizer mixtures wereapplied on thesurface of soil (Latossolo Vermel ho distrófico, medium/ sandy texture) in plastic pots $\left(400 \mathrm{~cm}^{3}\right)$. Volatilized $\mathrm{NH}_{3}-\mathrm{N}$ was collected on the $3^{\text {rd }}, 8^{\text {th }}, 15^{\text {th }}$ and $23^{\text {rd }}$ day after incubation in a flask containing sulfuric acid and methyl orange indicator. Variables that influence the quality of the fertilizer mixture, as hygroscopicity, granul ometry, and rest angle were al so evaluated. $\mathrm{NH}_{3}-\mathrm{N}$ volatil ization depends on the soil $\mathrm{pH}$. Themixture of urea $(330 \mathrm{mg}$ ) with ammonium sulfate $(300 \mathrm{mg})$ reduced thel osses of $\mathrm{NH}_{3}-\mathrm{N}$ significantly without affecting the mixture quality, in relation to the evaluated physical and chemical attributes. This mixture presented technical and agronomic efficiency for the proposed objective.
\end{abstract}

Index terms: nitrogen sources, ammonia losses, fertilizers mixture.

\section{INTRODUÇÃO}

O nitrogênio é o nutriente que mais limita a produtividadeagrícol a ea relação custo/benefício de interesse do agricultor, podendo também provocar prejuízos ao ambiente pel o el evado custo energético de produção das fontes nitrogenadas (Vitti et al., 1999). Estimativas realizadas indicam que os fertilizantes nitrogenados são responsáveis por $80 \%$ dos custos com fertilizantes e $30 \%$ de toda energia empregada na produção agrícola (Stangel, 1984).

A recuperação pelas plantas do nitrogênio fornecido por fertilizantes é inferior a $50 \%$ em relação à quantidade aplicada (Rao et al., 1992), sendo a volatilização um importante processo responsável pela baixa eficiência. As perdas de N$\mathrm{NH}_{3}$, quando a uréia é aplicada ao solo, pode representar 50 a $80 \%$ dototal de nitrogênio aplicado (Volk, 1959; Allison, 1965), cujo efeito é aumentado em plantio direto e em áreas canavieiras com colheita de cana crua (Wood, 1991; Oliveira et al., 1997; Lara Cabezas, 1998).

A volatilização de nitrogênio amoniacal $\left(\mathrm{N}-\mathrm{NH}_{3}\right)$, originado de fontes de $\mathrm{N}$ amídico (uréia), resulta da alcal inização da solução próxima ao grânulo durante sua hidrólise, catalisada pela enzima urease pela formação de íons bicarbonato $\left(\mathrm{HCO}_{3}{ }^{-}\right)$e hidroxila $\left(\mathrm{OH}^{-}\right)$. A el evação do $\mathrm{pH}$ da solução do solo poderá alcançar valores iguais a 10 (Nömmik \& Nilsson, 1963), favorecendo a transformação de $\mathrm{N}-\mathrm{NH}_{4}{ }^{+}$em $\mathrm{N}-\mathrm{NH}_{3}$ ea perda na forma de gás para a atmosfera.

O sulfato de amônio, fertilizante utilizado como fonte denitrogênio edeenxofre, nãosofre vol atilização de nitrogênio amoniacal $\left(\mathrm{N}-\mathrm{NH}_{3}\right)$ quando o $\mathrm{pH}$ é inferior a 7, mesmo sendo aplicado sobre restos de cultura (Volk, 1959). Considerandotal característica do sulfato deamônio, verificou-sequea recuperação de nitrogênio é mais eficiente quando a aplicação de uréia é real izada em mistura com sulfato de amônio no mesmo grânulo (Villas Bôas, 1995).

Medianteo uso de mistura de fontes nitrogenadas para minimizar perdas, devem-se avaliar os atributos físico-químicos que influem na qualidade dessas misturas. A higroscopicidade é a tendência do produto em absorver umidade da atmosfera (Sauchelli, 1960), afetando a qualidade dos fertilizantes por meio da redução da fluidez, decorrente do empedramento (Alcarde et al., 1992). O ângulo de repouso do produto é indicador de sua escoabilidade, influenciando a uniformidade da dose aplicada durante sua distribuição (Luz, 1997). A granulometria, determinada pelo tamanho e forma das partículas, tem ação sobre a segregação dos constituintes da mistura, com reflexos na higroscopicidade e escoabilidade em conseqüência da variabilidade de forma e tamanho das partículas.

O experimento objetivou avaliar a influência da adição de sulfato de amônio em mistura com a uréia sobre a volatilização $\left(\mathrm{N}-\mathrm{NH}_{3}\right)$, assumindo as seguintes hipóteses: (1) a mistura de fontes acidificantes (sulfato de amônio) com uréia, ainda queem mistura de grânulos eaplicada na superfície do solo, reduz a alcalinização da solução do solo (elevação do pH) durante a hidrólise da uréia e, conseqüentemente, a perda de nitrogênio amoniacal $\left(\mathrm{N}-\mathrm{NH}_{3}\right) ;(2)$ a influência sobre opH (parteda primeira hipótese) ea eficiência da apli cação superficial dessa 
mistura de grânulos (uréia e sulfato de amônio), dependem da dose de sulfato de amônio na composição da mistura e (3) a qualidade da mistura, em relação aos atributos físico-químicos, é variável conforme a composição da mistura.

\section{MATERIAL E MÉTODOS}

A pesquisa foi realizada em laboratórioclimatizado do Departamento de Sol os e Nutrição de Plantas da ESALQ/USP, no qual a temperatura foi mantida em $20^{\circ} \mathrm{C}$ no decorrer do experimento. Utilizou-se o Latossol o Vermel ho distrófico, cujos atributos físicos equími cos estão apresentados, respectivamente, nos quadros 1 e 2. Para análise dos atributos físicos, adotou-se o método proposto pela E MBRAPA (1997). As análises químicas foram realizadas de acordo com o método descrito por Raij et al. (1987), exceto a determinação de enxofre, real izada de acordo com o método relatado por Vitti (1988).
O experimento foi realizado em delineamento experimental inteiramentecasualizado, empregandose cinco tratamentos e cinco repetições. Os tratamentos foram constituídos pela mistura de $330 \mathrm{mg}$ de uréia (UR) com diferentes doses $(0,75$, 150, 225 e $300 \mathrm{mg}$ ) desulfato deamônio (SA), conforme apresentado no quadro 3. Para cada repetição, utilizaram-se $400 \mathrm{~cm}^{3}$ de solo acondicionados em recipientes plásticos. A pós aplicação dos tratamentos na superfície do solo, adicionou-se água até $50 \%$ da capacidade de campo ( $17 \mathrm{~mL} \mathrm{H}_{2} \mathrm{O} 400 \mathrm{~cm}^{-3}$ solo), repetindo-seessa operação durantea pesquisa, para manutenção da umidade do sistema. E m seguida, os recipientes foram isolados do ambiente em frascos cilíndricos de 3,2 litros hermeticamente fechados.

A determinação do nitrogênio amoniacal volatilizado foi feita em sistema fechado. Os recipientes plásticos, que continham $400 \mathrm{~cm}^{3}$ de solo, nos quais foram aplicados os tratamentos, foram colocados no interior dos frascos cilíndricos hermeticamentefechados. Além dos reci pientes com solo, recipientes com $25 \mathrm{~mL}$ de $\mathrm{H}_{2} \mathrm{SO}_{4} 0,1 \mathrm{~mol} \mathrm{~L}^{-1} \mathrm{e}$

Quadro 1. Resultados das análises físicas do solo em relação à distribuição granulométrica, classe textural e água retida a diferentes tensões

\begin{tabular}{|c|c|c|c|c|c|c|c|c|c|}
\hline \multirow{2}{*}{ Areia } & \multirow{2}{*}{ Silte } & \multirow{2}{*}{ Argila } & \multirow{2}{*}{ Classe textural } & \multicolumn{6}{|c|}{ Água retida - tensão (MPa) } \\
\hline & & & & 0,001 & 0,005 & 0,010 & 0,033 & 0,101 & 1,5 \\
\hline$\longrightarrow$ & $-\mathrm{g} \mathrm{kg}^{-1}$ & - & & 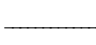 & 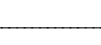 & $-\mathrm{kg}$ & 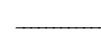 & 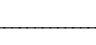 & - \\
\hline 820 & 20 & 160 & M édia/arenosa & 0,213 & 0,174 & 0,088 & 0,085 & 0,060 & 0,047 \\
\hline
\end{tabular}

Quadro 2. Resultados das análises químicas do Latossolo Vermelho-E scuro

\begin{tabular}{|c|c|c|c|c|c|c|c|c|c|c|c|c|}
\hline pH & M.o. & $\mathbf{P}$ & $\mathbf{S}$ & $\mathbf{K}$ & $\mathrm{Ca}$ & Mg & Al & $\mathbf{H}+\mathbf{A l}$ & $\mathbf{S}$ & $\mathbf{T}$ & $\mathbf{v}$ & $\mathbf{m}$ \\
\hline $\mathrm{CaCl}_{2}$ & $\mathrm{~g} \mathrm{dm}^{-3}$ & \multicolumn{2}{|c|}{$-\mathrm{mg} \mathrm{dm}^{-3}$} & \multicolumn{7}{|c|}{$-\mathrm{mmol}_{\mathrm{c}} \mathrm{dm}^{-3}$} & \multicolumn{2}{|c|}{ - $\%$} \\
\hline 3,8 & 12,0 & 3,0 & 11,0 & 0,6 & 1,0 & 1,0 & 9,0 & 34,0 & 2,6 & 36,6 & 7,0 & 78,0 \\
\hline
\end{tabular}

Quadro 3. Tratamentos empregados para avaliar a volatilização (V) da amônia

\begin{tabular}{|c|c|c|c|c|c|}
\hline Tratamento & $\mathbf{N}-\mathbf{N H}_{4}{ }^{+}$ & N-amídico & N-total & $\mathbf{S}$ & N/S \\
\hline $\mathrm{mg} 400 \mathrm{~cm}^{-3}$ & 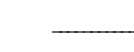 & mg 400 & TFSA - & - & \\
\hline $\begin{array}{l}V 1=0 S A+330 U R \\
V 2=75 S A+330 U R \\
V 3=150 S A+330 U R \\
V 4=225 S A+330 U R \\
V 5=300 S A+330 U R\end{array}$ & $\begin{array}{l}- \\
16 \\
32 \\
48 \\
64\end{array}$ & $\begin{array}{l}150 \\
150 \\
150 \\
150 \\
150\end{array}$ & $\begin{array}{l}150 \\
166 \\
182 \\
198 \\
214\end{array}$ & $\begin{array}{l}- \\
18 \\
36 \\
54 \\
72\end{array}$ & $\begin{array}{l}- \\
9,22 \\
5,02 \\
3,65 \\
2,95\end{array}$ \\
\hline
\end{tabular}


2 gotas do indicador alaranjado de metila também foram colocados no interior dos frascos cilíndricos (Figura 1). O ácido e o indicador foram utilizados para avaliar a reação e quantificação da amônia liberada. A solução ácida utilizada na coleta da amônia volatilizada posteriormentefoi titulada com $\mathrm{NaOH} 0,025 \mathrm{~mol} \mathrm{~L}^{-1}$ para quantificar o $\mathrm{N}-\mathrm{NH}_{3}$ retido.

As determinações de $\mathrm{N}-\mathrm{NH}_{3}$ volatilizado foram realizadas aos 3, 8, 15, e 23 dias após aplicação da mistura de fertilizantes e, na sua quantificação, utilizou-se o fator 0,35 para a conversão de meq em mg de $\mathrm{N}-\mathrm{NH}_{3}$, conforme a expressão (1):

$$
\mathrm{N}-\mathrm{NH}_{3}=\left(\mathrm{V}_{\text {branco }}-\mathrm{V}_{\text {amostra }}\right) 0,35
$$

em que $\mathrm{N}-\mathrm{NH}_{3}$ éa quantidade de $\mathrm{N}$ volatilizado $(\mathrm{mg})$, $\mathrm{V}_{\text {branco }}$ corresponde ao volume de base consumida na titulação em branco e $V_{\text {amostra }}$ ao volume utilizado para a titulação das amostras. O fator 0,35 foi obtido a partir dos seguintes cálculos:

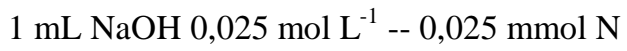

$$
\begin{gathered}
\left(\mathrm{V}_{\text {branco }}-\mathrm{V}_{\text {amostra }}\right)--------\mathrm{X} \\
1 \mathrm{mmol} \mathrm{N}=14 \mathrm{mg} \mathrm{N} \\
\mathrm{mg} \mathrm{N} / 14=\left(\mathrm{V}_{\text {branco }}-\mathrm{V}_{\text {amostra }}\right) 0,025 \\
\mathrm{mg} \mathrm{N}=\left(\mathrm{V}_{\text {branco }}-\mathrm{V}_{\text {amostra }}\right) \times 0,35
\end{gathered}
$$

Para avaliar a volatilização no período de tempo estudado, aplicou-se regressão pol inomial, adotandose a de maior grau de significância. Além da análise de regressão, os resultados das avaliações de volatilização foram submetidos à análise da variância, utilizando o teste $\mathrm{F}$ a 99 \% de confiança. Para as causas de variação em que $F$ apresentou val or significativo, realizou-se o teste deTukey para comparação das médias dos tratamentos.
A variação do $\mathrm{pH}$ do solo, dependendo das misturas defertilizantes utilizadas, esua influência no processo de volatilização $\left(\mathrm{N}-\mathrm{NH}_{3}\right)$ foram avaliadas aos 23 dias da incubação. $\mathrm{O}$ pH foi determinado de acordo com o método proposto por Raij et al. (1987), utilizando amostras desol o col etadas na profundidade de $0-1 \mathrm{~cm}$ com auxílio de minissonda, para maior precisão na amostragem, repetindo-se o procedimento até obtenção de $20 \mathrm{~g}$ de solo de cada repetição.

Para avaliar a qualidade da mistura degrânulos, foram efetuados testes relativos aos atributos físicoquímicos. O cálculo do ângulo de repouso foi realizado em misturas semelhantes àquelas utilizadas para determinar a volatilização de $\mathrm{N}-\mathrm{NH}_{3}$ (V1, V2, V3, V4 eV5), adotando-se quatro repetições. U ma amostra de $400 \mathrm{~cm}^{3}$ da mistura de fertilizantes foi distribuída no equipamento utilizado para essa finalidade, com formato retangular e parede de vidro com escala horizontal $(\mathrm{cm})$ e vertical $(\mathrm{cm})$. A distribuição das misturas de fertilizantes (amostras, $400 \mathrm{~cm}^{3}$ ) no interior do equi pamento, a partir dolado esquerdo e junto à parede lateral (menor dimensão do retângulo), origina uma figura geométrica na forma de triângulo retângulo, cujo ângulo reto é formado entre a lateral e o fundo do equipamento. A partir das medidas das dimensões, vertical (altura dotriângulo, cm) e horizontal (base do triângulo, cm), delimitadas pela amostra depositada no interior do equipamento, calculou-se o valor do ângulo de repouso (Luz, 1997), conforme a expressão (2):

$$
\alpha=\operatorname{arctg} \text { (escala vertical/escala horizontal) }
$$

em que a escala vertical corresponde à altura do triângulo $(\mathrm{cm})$ e a escala horizontal à base do triângulo $(\mathrm{cm})$ da figura geométrica formada pela deposição da amostra no interior do equipamento.

A higroscopicidade $(\mathrm{H})$ da mistura foi determinada em quatrotratamentos, com quatro repetições de cada, diferentes daqueles utilizados para avaliação da volatilização: H 1 - 100 \% uréia (330mg); H2 - 100 \%

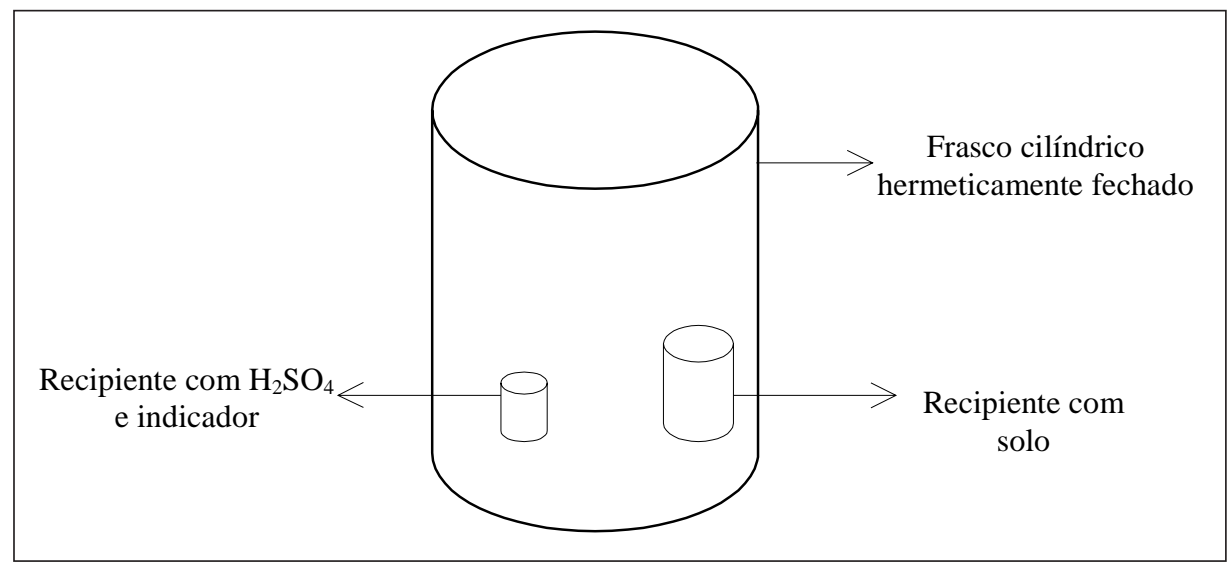

Figura 1. Representação esquemática do sistema utilizado na coleta da amônia volatilizada. 
sulfato de amônio (300mg); H3 - 82 \% uréia +18 \% sulfato de amônio $(270,6$ + 54 mg) e H 4 - 52 \% uréia +48 \% sulfato de amônio (171,6 + 144 mg).

Os tratamentos foram colocados em quatro ambientes com diferentes umidades $(81,1 ; 78,1 ; 69,5$ e 58,0\%), mantidas constantes através de dessecadores de $250 \mathrm{~mm}$ de diâmetro que continham solução de ácido sulfúrico com diferentes concentrações: $2,9 \mathrm{~mol} \mathrm{~L}^{-1}, 3,59 \mathrm{~mol} \mathrm{~L}^{-1}, 33 \mathrm{~mol} \mathrm{~L}^{-1} \mathrm{e}$ $5,28 \mathrm{~mol} \mathrm{~L}^{-1}$, respectivamente, padronizadas com $\mathrm{NaOH} 0,01 \mathrm{~mol} \mathrm{~L}^{-1}$. Amostras das misturas de cada tratamento foram col ocadas em reci pientes plásticos com $4 \mathrm{~cm}$ de diâmetro $1 \mathrm{~cm}$ de al tura e submetidas à secagem em estufa a $50{ }^{\circ} \mathrm{C}$ durante $24 \mathrm{~h}$, determinando-se, ao final, a massa da matéria seca das amostras. Em seguida, foram colocadas em quatro ambientes diferentes, em relação à umidade relativa (quatro repetições de cada mistura para cada umidade relativa), em reci pientes hermeticamente fechados, durante 4, 8, 24, 48, 72 e $144 \mathrm{~h}$. Ao final do período, procedeu-se à determinação da massa de cada amostra (mistura defertilizantes +água), assim como da água absorvida (U%), calculada em relação à massa da amostra seca, conforme a expressão (3):

$$
\mathrm{U}=\left[\left(\mathrm{P}_{\mathrm{u}}-\mathrm{P}_{\mathrm{s}}\right) / \mathrm{P}_{\mathrm{s}}\right] 100
$$

em que $U$ corresponde à umidade relativa da amostra (\%), $\mathrm{P}_{\mathrm{u}}$ à massa fresca da amostra $(\mathrm{g})$ e $\mathrm{P}_{\mathrm{s}}$ à massa seca da mesma amostra após a secagem em estufa ( $\mathrm{g}$ ).

A anál ise granulométrica foi realizada em quatro tratamentos $(\mathrm{H} 1, \mathrm{H} 2, \mathrm{H} 3 \mathrm{eH} 4)$, os mesmos adotados para o estudo da higroscopicidade da mistura, utilizando agitador mecânico com jogo de peneiras previamente sel ecionadas (ABNT 4-4,76 mm; ABNT 10-2,0 mm; ABNT 18-1,0 mm; ABNT 20-0,84 mm; ABNT 35-0,5 mm; e, ABNT 50-0,3 mm). U ma amostra de $400 \mathrm{~cm}^{3}$ de cada mistura, cuja massa fora previamente determinada, foi submetida à agitação mecânica (125 rpm) durante três minutos. Posteriormente, determinou-se a massa das frações retidas nas diferentes peneiras, obtendo-se a distribuição granulométrica das misturas de fertilizantes.

\section{RESULTADOS E DISCUSSÃO}

Os resultados determinados para a perda de nitrogênio por volatilização encontram-se no quadro 4.

De acordo com os resultados, a intensidade máxima de vol atilização de $\mathrm{N}-\mathrm{NH}_{3}$ da uréia ocorreu no período entre o 30 e o 90 dia após a incubação da mistura, alcançando valores superiores a $75 \%$ em relação ao total de nitrogênio volatilizado (Quadro 4). Aos três dias de incubação, as perdas de $\mathrm{N}-\mathrm{NH}_{3}$ em relação às perdas totais (acumulada em 23 dias) foram iguais a 50,6 (V1); 48,4 (V2); 43,6 (V3); 46,6 (V4) e $37,0 \%$ (V5).

Oito dias após a incubação, esses valores caíram para 28,6 (V1); 31,0 (V2); 35,6 (V3); 36,1 (V4) e 39,8 \% (V5), indicando que as maiores perdas são verificadas logo após a adição do fertilizante no solo, evidenciando que a hidrólise da uréia éum processo rápido. Sengik (1993) verificou que a intensidade máxima de perdas de $\mathrm{N}-\mathrm{NH}_{3}$ ocorreu nos primeiros cinco dias após aplicação de resíduos utilizados como fonte de nitrogênio.

A perda de nitrogênio amoniacal atéo $8^{\circ}$ dia para o tratamento $\mathrm{V} 1$ em relação ao total acumulado no período ( 23 dias) foi igual a $79,2 \%$ do nitrogênio volatilizado. Pinna \& Valdívia (1978) registraram

Quadro 4. Perdas de N-NH ${ }_{3}$, considerando as misturas de fertilizantes (uréia e sulfato de amônio) aplicadas na superfície de $400 \mathrm{~cm}^{3}$ de solo, após diferentes períodos de incubação (dias)

\begin{tabular}{|c|c|c|c|c|c|c|c|}
\hline \multirow{2}{*}{ Tratamento } & \multirow{2}{*}{\multicolumn{2}{|c|}{$\mathbf{N}-\mathrm{NH}_{4}{ }^{+}$}} & \multicolumn{5}{|c|}{ Volatilização ( mg N-NH} \\
\hline & & & 3 dias & 8 dias & 15dias & 23 dias & Total \\
\hline
\end{tabular}

\begin{tabular}{|c|c|c|c|c|c|c|c|}
\hline \multicolumn{8}{|c|}{$\mathrm{mg} 400 \mathrm{~cm}^{-3}$ solo } \\
\hline V1 & - & 150 & $61,51 a$ & $34,79 b$ & $20,23 a$ & 4,99ab 121,52 & $y=-0,20 x^{2}+8,20 x+38,83 \quad R^{2}=1$ \\
\hline V2 & 16 & 150 & $61,49 a$ & $39,35 a b$ & $20,93 a$ & $5,32 a \quad 127,09$ & $y=-0,22 x^{2}+9,09 x+36,48 \quad R^{2}=0,99$ \\
\hline V3 & 32 & 150 & $49,42 b$ & $40,34 a b$ & $19,46 a$ & $4,20 b c 113,42$ & $y=0,23 x^{2}+9,25 x+24,20 \quad R^{2}=0,99$ \\
\hline V4 & 48 & 150 & $53,06 b$ & $41,05 a$ & $16,16 a$ & $3,61 \mathrm{~cd} \quad 113,88$ & $y=-0,24 x^{2}+9,15 x+28,59 R^{2}=0,99$ \\
\hline V5 & 64 & 150 & $36,03 c$ & $38,74 a b$ & $19,59 a$ & $3,11 d \quad 97,47$ & $y=-0,23 x^{2}+9,05 x+11,23 \quad R^{2}=0,99$ \\
\hline Teste F (1 \%) & & & $86,11^{* *}$ & $3,05^{* *}$ & $1,00 * *$ & $20,13^{* *}$ & \\
\hline C.V. ( \%) & & & 4,85 & 8,05 & 21,25 & 10,83 & \\
\hline
\end{tabular}

** Significativo pelo teste $\mathrm{F}$ a $1 \%$. Médias seguidas de letras minúsculas diferentes, na mesma coluna, diferem estatisticamente entre si pelo teste de Tukey $(p<0,01)$. 
$70 \%$ de perda de $\mathrm{N}-\mathrm{NH}_{3}$ da uréia por volatilização após quatro dias de sua aplicação, tendo observado que as perdas eram menores em $\mathrm{pH}$ ácido.

A adição de sulfato de amônio em mistura com uréia reduziu a volatilização de $\mathrm{N}-\mathrm{NH}_{3}$, principalmente no tratamento V5, determinando-se perda total de 97,47 mg N-NH${ }_{3}$, enquanto o tratamento 1 resultou em 121,52 mg de $\mathrm{N}-\mathrm{NH}_{3}$.

Na mistura representada pel o tratamento V5, a perda de nitrogênio três dias após a incubação foi significativamente reduzi da em comparação com a dos demais tratamentos, sendo 41,4 \% inferior ao V1, confirmando a hipótese de que uréia e sulfato de amônio, ainda que em mistura de grânulos e aplicados na superfície do solo, reduzem a perda de amônia proveniente da uréia.

Considerando as quantidades totais de nitrogênio aplicadas em cada tratamento, as percentagens de perdas em V1, V2, V3, V4 eV5 foram de 81, 77, 62, 58 e $46 \%$, respectivamente. A eficiência de aproveitamento em V1 foi de $19 \%$ enquanto em V 5 foi de $46 \%$.

A mistura caracterizada pelo tratamento V5 diminuiu as perdas de $\mathrm{N}-\mathrm{NH}_{3}$ por volatilização em $35 \%$. Watson (1987) verificou redução de $21 \%$ nas perdas quando misturou uréia com nitrato de amônio. A mistura de uréia com sulfato de amônio diminuiu as perdas de $\mathrm{N}-\mathrm{NH}_{3}$ por volatilização em 38 \% (Watson 1988).

Os resultados evidenciam que a eficiência da aplicação superficial da mistura de grânul os depende da dose de sulfato de amônio utilizada na mistura com uréia, confirmando a segunda hipótese deste trabalho.

De acordo com a figura 2, o pH do solo diminuiu com a adição de sulfato de amônio na mistura com uréia, apresentando variação de 1,1 unidade. 0 solo do tratamento $\mathrm{V} 1$ apresentou pH igual a 6,1 (23 dias após a incubação), enquanto o tratamento V5 provocou o abaixamento do $\mathrm{pH}$ a 5,0. Segundo Hargrove (1988), o pH do soloéo fator quetem maior influência na perda de nitrogênio por volatilização, portanto a presença de fertilizantes acidificantes em mistura com uréia diminui as perdas de $\mathrm{N}-\mathrm{NH}_{3}$ (Villas Bôas, 1995).

A diferença observada para a perda total de $\mathrm{N}$ $\mathrm{NH}_{3}$, verificada entre os tratamentos V1 e V5, foi, aproximadamente, $20 \%$ inferior. Esse resultado também foi constatado por Filimonov \& Strel nikova (1974), os quais obtiveram $20 \%$ de perda de $\mathrm{N}-\mathrm{NH}_{3}$ por volatilização proveniente da uréia em solo com pH próximo da neutralidade e apenas $4 \%$ em solo ácido.

Os valores obtidos para ângulo de repouso, considerando os tratamentos, são apresentados na figura 3. Observa-se que o menor valor para esse atributo foi verificado para o tratamento exclusivo com uréia (35,69), confirmando resultados obtidos por Luz (1997), o qual encontrou valores iguais a 35,8응 (uréia) e 39,6o para a fórmula N-P-K (6-12-6). O ângulo de repouso varia com o tamanho e forma da partícula ecom o grau dehigroscopicidade do produto; assim, o menor valor para a uréia indica que sua escoabilidadeésuperior às misturas que receberam sulfato de amônio, uma vez que suas partículas são maiores, apresentam tamanho regular e menor higroscopicidade em relação às misturas (Figura 3).

O ângulo de repouso aumentou até à dose de 75 mg de sulfato de amônio em mistura com uréia e não sofreu grande variação quando as doses foram superiores a $75 \mathrm{mg}$. Portanto, pode-se afirmar quea mistura entre as referidas fontes (uréia e sulfato de amônio) étecnicamente viável, não comprometendo a escoabilidade ou fluidez da mistura, assim como o aspecto agronômico, uma vez que a uniformidade de aplicação pode ser mantida.

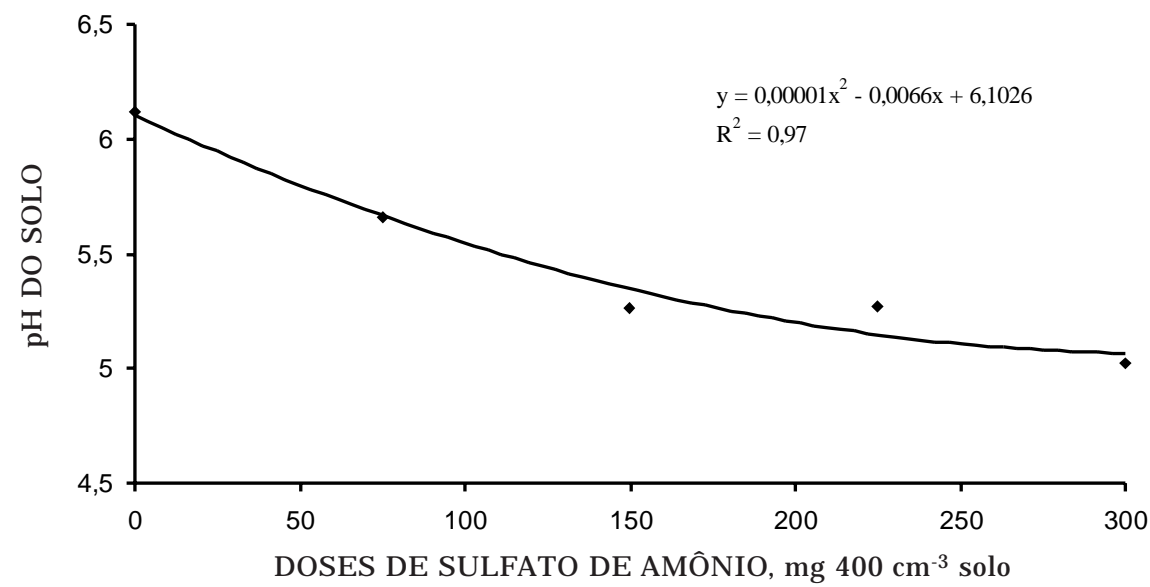

Figura 2. Valores de pH do solo, considerando as doses de sulfato de amônio presente nas misturas após 23 dias de incubação. 


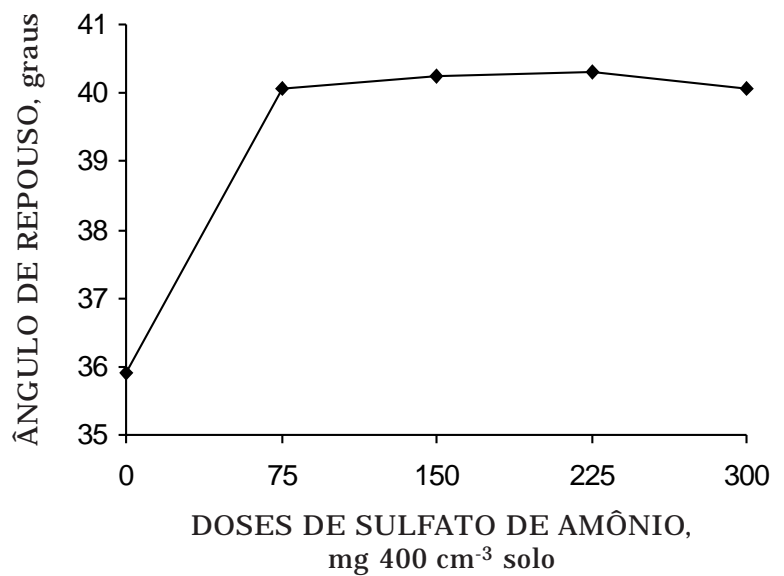

Figura 3. Valores obtidos para ângulo de repouso, considerando a dose de sulfato de amônio presente na mistura de fertilizantes.

Verificou-se que a absorção de umidade variou de acordo com o teor de umi dade ambiente, do tempo deexposiçãoe composi ção da mistura de fertilizantes $\mathrm{H} 1, \mathrm{H} 2, \mathrm{H} 3$ e H4. O aumento da umidade do ambiente e do tempo de exposição do fertilizante aumentou a quantidade de água absorvida.

Nas figuras 4, 5 e6, verifica-seque os tratamentos que apresentaram maiores valores médios de absorção de água da atmosfera nas umidades relativas de 85,1, 78,1 e 69,5\% foram H3 e H4. A maior quantidade de água absorvida foi de $31,4 \%$ (H3) na umidade relativa de 85,1 \% com exposição igual a $144 \mathrm{~h}$, indicando diminuição da umidade crítica em decorrência da mistura desses fertilizantes (Figura 4).

$\mathrm{O}$ tratamento $\mathrm{H} 2$ apresentou menores teores médios de absorção de água para as umidades relativas de 85,1 e 78,1 \%, para qualquer tempo de exposição, evidenciando quea umidade crítica desse fertilizante é superior à da uréia e da mistura entre ambos, ocasionando menor higroscopicidade (Figuras 4 e 5). Esses resultados apresentam concordância com os valores obtidos pelo T.V.A. (1970), em que a umidade crítica da uréia, sulfato de amônio e da mistura entre ambos (1:1) a $30{ }^{\circ} \mathrm{C}$ é, respectivamente, de 75,2, 79,2 e 59,4 \% (UR).

A maior absorção deágua da atmosfera verificada pelas misturas de uréia com sulfato de amônio não inviabiliza a utilização dessas misturas, uma vez que, em condições de campo, o tempo de exposição das misturas à umidade relativa é inferior a $24 \mathrm{~h}$, enquanto a diferença entre as misturas se acentua depois desse período. Portanto, pode-se afirmar que a sua utilização é viável, sem prejuízos para a qualidade do produto e para a operacionalidade da aplicação.

Para a umidaderelativa de 58 \%, nãose constatou absorção de água para todos os tratamentos,

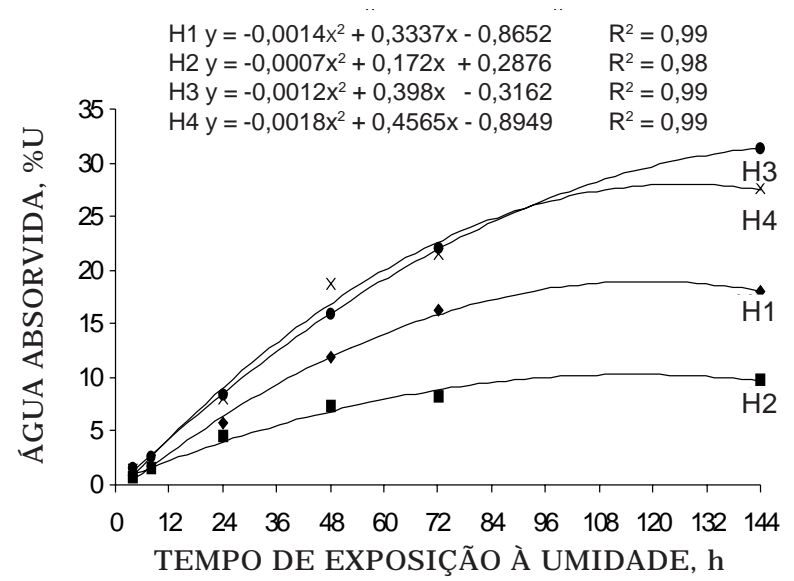

Figura 4. Valores médios de absorção de água (U\%) pelas misturas de fertilizantes, considerando o tempo de exposição à umidade relativa de $85,1 \%$.

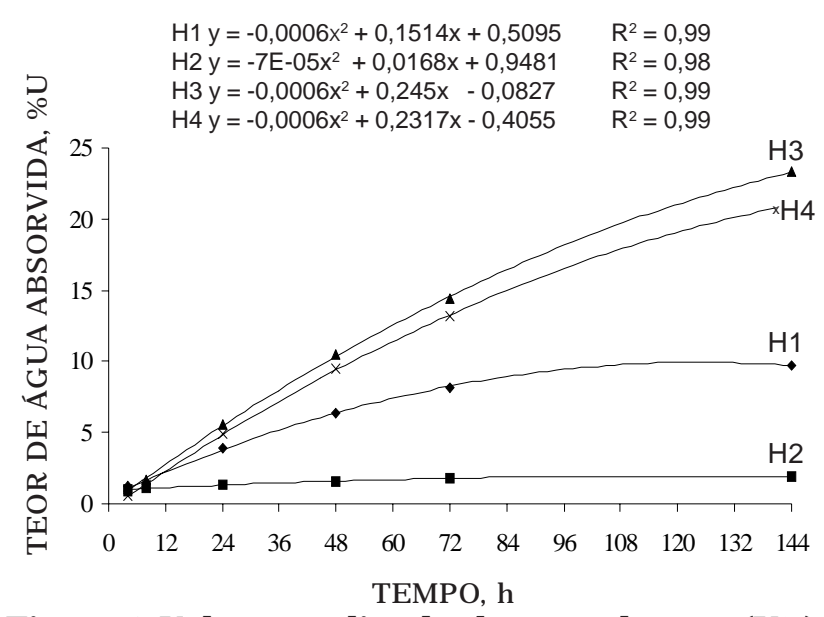

Figura 5. Valores médios de absorção de água (U\%) pelas misturas de fertilizantes, considerando o tempo de exposição à umidade relativa de $78,1 \%$

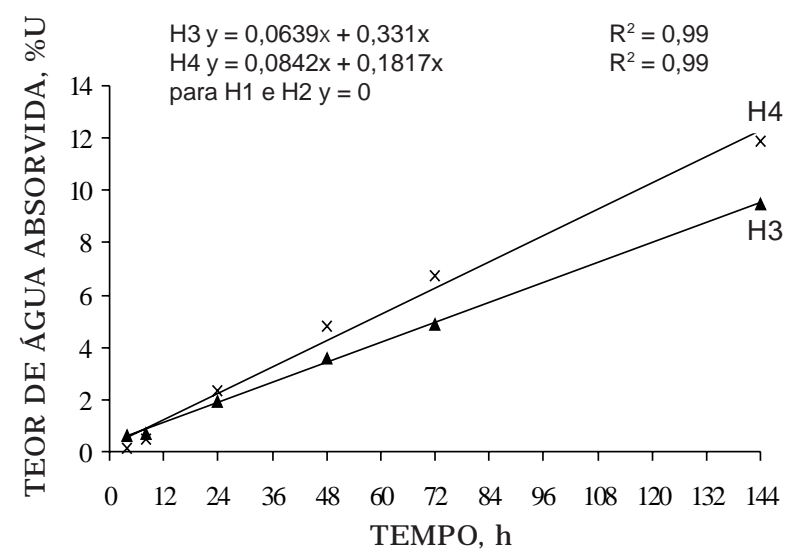

Figura 6. Valores médios de absorção de água (U\%) pelas misturas de fertilizantes $\mathrm{H} 3$ e $\mathrm{H} 4$, considerando o tempo de exposi ção à umidade relativa de $69,5 \%$. 


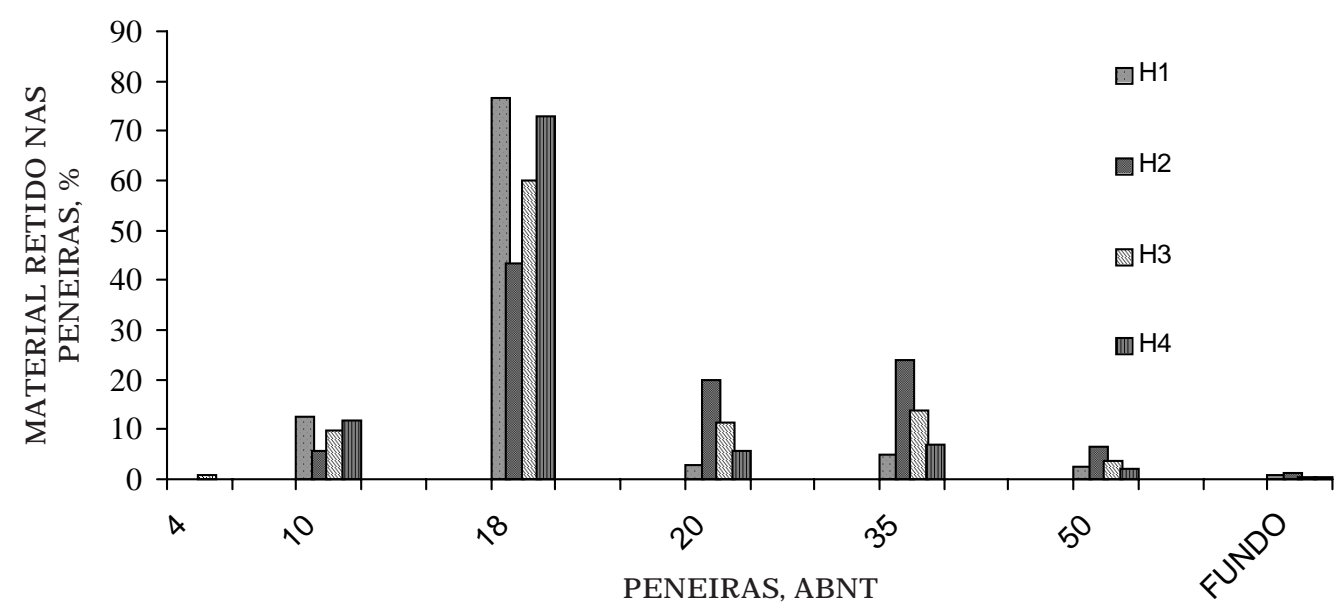

Figura 7. Granulometria dos materiais nos tratamentos, conforme as peneiras utilizadas AB NT 4, 10, 18, 20, 35 e 50.

independentemente do tempo de exposição do produto à umidade. Também não se observou absorção de umidade pela uréia e pelo sulfato de amônio na umi dade de 69,5 \%. Tais constatações são explicadas pelo fato de que na umidade de 58 e $69,5 \%$ não foi atingida umidade crítica dos produtos avaliados.

Os resultados doteste de granul ometria realizado nos tratamentos constituídos para a avaliação da higroscopicidade estão apresentados na figura 7.

Os tratamentos $\mathrm{H} 1$ e $\mathrm{H} 4$ apresentaram, respectivamente, 12,30 e $11,65 \%$ da amostra retida na peneira ABNT 10; 76,67 e 73,12\% na peneira ABNT 18. Nas demais peneiras a quantidade da amostra retida não ultrapassou $5 \%$, apresentando na peneira ABNT 4 e no fundo do agitador uma participação inferior a 0,8 \%, para ambos os tratamentos.

A amostra do tratamento $\mathrm{H} 2$ apresentou $43,22 \%$ da quantidade da amostra retida na peneira ABNT 18; 19, $81 \%$ na peneira ABNT 20; 23,75\% na peneira ABNT 35 e o restante (inferior a $6 \%$ ) nas demais peneiras. A mistura $\mathrm{H} 3$ apresentou $85,53 \%$ da amostra retida nas peneiras ABNT 18; 20 e 35, permanecendo retida, respectivamente, 60,1 , 11,5 e $13,97 \%$ da amostra.

Esses dados estão de acordo com as exigências constantes na Portaria no 01, de 04/03/83 (Brasil, 1983), que especifica a natureza física dos fertilizantes, em cuja classificação a uréia granulada não deve ser retida na peneira ABNT 4 (100\%) e até $5 \%$ na peneira ABNT 35, podendo ser estendido para a mistura $82 \%$ de uréia $+18 \%$ de sulfato de amônio (H4). O sulfato de amônio, classificado como farelado, não deve ficar retido na peneira ABNT 4 ( $100 \%$ ) e $20 \%$ retido na peneira ABNT 7, podendo ser estendido para a mistura de $52 \%$ de uréia $+48 \%$ de sulfato de amônio (H3).
De acordo com os resultados da distribuição granul ométrica para as misturas aval iadas, verificase que elas se encontram dentro das exigências da legisl ação, apresentando cerca de $70 \%$ das amostras das misturas retidas na mesma peneira (ABNT 18), evidenciando a uniformidade em sua aplicação.

\section{CONCLUSÕES}

1. A mistura de uréia com sulfato de amônio é viável, pois proporciona diminuição das perdas de $\mathrm{N}-\mathrm{NH}_{3}$ por volatilização.

2. Os atributos físicos, como ângulo de repouso, higroscopicidade e granul ometria, não são afetados a ponto de inviabilizar a utilização da mistura de uréia com sulfato de amônio.

\section{LITE RATURA CITADA}

ALCARDE,J.C.; MALAVOLTA, E.; BORGES,A.L.; MUNIZ,A.S.; VELOSO, C.A.; FABRÍ CIO, A.C. \& VIEGAS, J.M. Avaliação da higroscopicidade de fertilizantes e corretivos. Sci. Agric., 49:137-144p. 1992.

ALLISON, F.E. Evaluation of incoming and outgoing processes that effect soil nitrogen. In: BARTHOLOMEW, W.V. \& CLARK, F.E., eds. Soil nitrogen. Madison, American Society of Agronomy, 1965. p.573-615.

BRASIL. Ministério da Agricultura. Divisão de corretivos e fertilizantes. Inspeção e fiscalização da produção e do comércio de fertilizantes, corretivos, inoculantes e estimulantes ou biofertilizantes destinados à agricultura. Legislação. Portaria no 84182. Portaria o 01/83. Brasília, 1983. 88p.

EMPRESA BRASILEIRA DE PESQUISA AGROPECUÁRIA EMBRAPA. Centro nacional de pesquisas de solos. Manual de métodos de análise de solo. 2.ed. Planaltina, 1997. 212p. (Documentos, 1) 
FILIMONOV, D.A. \& STRELNIKOVA, R.A. Gaseous losses of ammonia following surface application of urea. Sov. Soil Sc., 6:426-32, 1974.

HARGROVE, W.L. Soil, environmental, and management factors influencing ammonia volatilization under field conditions. In: BOCK, B.R. \& KISSEL, D.E., eds. Ammonia volatilization from urea fertilizers. Alabama, NFDC, TVA. 1988. p.17-36.

LARA CABEZAS, W.A.R. Comportamento dos adubos nitrogenados em clima e solo de Cerrado. R. Plantio Direto, maio/junho: 52-60, 1998.

LUZ, P.H.C. Determinação do ângulo de repouso de fertilizantes e corretivos. Disciplina: técnicas alternativas para o fornecimento de nutrientes para as plantas (LSO-580). Piracicaba, Escola Superior de Agricultura "Luiz de Queiroz", 1997. 8p.

NÖMMIK, H. \& NILSSON, K.O. Nitrification and movement of anhydrous ammonia in soil. Acta Agric. Scand., 13:205-219, 1963.

OLIVEIRA, M.W.; GAVA, G.J .C.;VITTI,A.C.; BENDASSOLI,J .A. \& TRIVELIN, P.C.O. Volatilização de amônia proveniente da uréia $\left({ }^{15} \mathrm{~N}\right)$ aplicada em um solo cultivado com cana-deaçúcar. In: ENCONTRO CIENTÍFICO DE PÓSGRADUANDOS DO CENA/USP, 3., Piracicaba, 1997. Anais, Piracicaba, Universidade de São Paulo, 1997. p.28.

PINNA,J .C. \& VALDÍ VIA, S.V. Nitrogen volatilization from urea applied as a top dressing or buried in calcareous sugarcane soils. In: CONGRESS OF THE INTERNATIONAL SOCIETY OF SUGARCANE TECHNOLOGISTS, 17., São Paulo, 1977. Proceedings. São Paulo, I mpress, 1978. v.2. p.1455-61.

RAIJ, B. van; GUAGGIO, J.A. \& CANTARELLA, H. Análise química do solo para fins de fertilidade. Campinas, Fundação Cargill e Instituto Agronômico, 1987. 170p.

RAO, A.C.S.; SMITH, J.L.; PARR, J.F. \& PAPENDICK, R.I. Considerations in estimating nitrogen recovery efficiency by the difference and isotopic dilution methods. Fer.Res., 33:209-217, 1992.
SAUCHELLI, V. Chemistry and technology of fertilizers.. New York, Reinhold, 1960. 692p.

SENGIK, E. Efeito de resíduos orgânicos e de sais inorgânicos na volatilização de amônia em solo tratado com uréia. Piracicaba, Escola Superior de Agricultura "Luiz de Queiroz", 1993. 136p. (Tese de Doutorado)

STANGEL, P.J. World nitrogen situation, trends, outlook, and requirements. In: HANCK, R.D., ed. Nitrogen in crop production. Madison, American Society Agronomy, 1984. p.23-54.

TENNESSEE VALLEY AUTHORITY - TVA. Procedures for determinning physical properties of fertilizers. Alabama, Muscle Shoals, 1970.17p. (Special reports, 5444)

VILLAS BÔAS, R.L. Recuperação do nitrogênio da uréia pelo milho: efeito da mistura com sulfato de amônio, da dose e do modo de aplicação. Piracicaba, Escola Superior deAgricultura "Luiz de Queiroz", 1995. 128p. (Tese de Doutorado)

VITTI, G.C. Avaliação e interpretação do enxofre no solo e na planta. J aboticabal, Fundação de Estudos e Pesquisas em Agronomia, Medicina Veterinária e Zootecnia, 1988. 37p.

VITTI, G.C.; FAVARIN, J .L.; RESENDE, L.O.; \& TREVISAN, W. Manejo do nitrogênio em diversos sistemas de produção agrícola. Piracicaba, Serrana/FEALQ/GAPE, 1999. 38p.

VOLK, G.M. Volatile loss of ammonia following surface application of urea to turf on base soils. Agron. J., 51:746749, 1959

WATSON, C.J. The comparative effect of a mixed urea, ammonium nitrate, ammonium sulphate granular formulation on the efficiency of $\mathrm{N}$ recovery by perennial ryegrass. Fert. Res., 14:193-204, 1987.

WATSON, C.J . An assessment of granular urea/ammonium sulphate and urea/potassium nitratefertilizers on nitrogen recovery by ryegrass. Fert. Res., 18:19-29, 1988.

WOOD, A.W. Management of crop following green harvesting of sugarcane in N orth Queensland. Soil \& Till. Res., 20:69-85, 1991. 
G.C. VITTI et al.

R. Bras. Ci. Solo, 26:663-671, 2002 